\title{
O EMPOWERMENT NA ADMINISTRAÇÃO DE UNIDADES DE INFORMAÇÃO
}

\author{
Raquel RUTINA* \\ rutina@coruja.humanas.ufpr.br \\ Edmeire Cristina PEREIRA* \\ edmeire@coruja.humanas.ufpr.br
}

RESUMO

\begin{abstract}
Apresenta estudo da Administração em Unidades de Informação, enfocando o lado humano dos gestores de informação, envolvendo as dimensões psicológica e sociológica de seu trabalho. Objetiva evidenciar um panorama da gestão de recursos humanos de forma estratégica, desenvolver uma nova visão no gerenciamento de pessoas, que possibilite satisfazer suas necessidades e crescimento pessoal e grupal e analisar a prática gerencial corrente levando-se em consideração os desafios que o futuro exige das empresas/unidades de informação triunfadoras.
\end{abstract}

Palavras-chave: Unidades de Informação - Gestão - Empowerment

\section{ABSTRACT}

This paper presents a study of Information Unit administration focusing the information managers' human side, involving the psychological and sociological work dimensions. It aims to make evident a human resources administration scenario in a strategic way, to develop a new vision of personnel management in order to meet their needs of personal and group growth, and to analyze the current managerial practices taking in consideration the challenges that the future will demand from the successful information unit organizations.

Keywords: Information units; Empowerment; management.

\section{INTRODUÇÃO}

"Muitas são as maravilhas e nenhuma é mais maravilhosa do que o homem".

$$
\text { SÓFOCLES - "Antígona" }
$$

Muito se fala e escreve nos últimos tempos sobre as novas tecnologias de informação e comunicação, porém, percebemos que o lado humano dos gestores de empresas/unidades de informação tem ficado um pouco a desejar nos aspectos psicológico e sociológico de seu trabalho.

O conceito moderno hoje de empresa/ unidade de informação passa pelo trinômio: integração de recursos humanos, agregação de valor aos seu produtos e/ou serviços e missão

\footnotetext{
") Professoras do Curso de Gestão da Informação, da Universidade Federal do Paraná. Mestrandas em Biblioteconomia pela PUC-Campinas. Rua General Carneiro 460, 7o andar - Centro - Curitiba / PR - 81.060-150
} 
social bem delineada, na comunidade em que se encontra inserida.

Logo, para que uma empresa/unidade de informação trabalhe dentro dessa nova filosofia (mentalidade), haverá a necessidade de profissionais dotados de capacidade de percepção da realidade externa à empresa (macroeconomia) e, também, de seu microcosmo interno. Consultores de recursos humanos são unânimes em afirmar que o que quebra uma empresa atualmente é a sua incapacidade de adaptação, ou seja, a sua hesitação em quebrar barreiras, em provocar rupturas necessárias, ou mesmo, de não aproveitar os momentos de crise para criar novas oportunidades.

Lamentavelmente, são poucas as empresas privadas de pequeno e médio portes e instituições públicas no Brasil que se preocupam em saber administrar pessoas para alcançar a qualidade de seu produtos e serviços em todos os níveis. A febre da normalização ISO 9000 parece ter atacado apenas as empresas multinacionais, ainda.

Portanto, o enfoque deste artigo será: NOVOS DESAFIOS E ATRIBUTOS DE RELACIONAMENTOS DOS GESTORES DE SUCESSO, pois vivemos numa época do compartilhamento de idéias, negócios e emoções e, sem o quê, a empresa inteligente não é passível de acontecer e desenvolver o seu QI grupal. Nunca é demais frisar que, hoje em dia, qualidade é premissa e não mais diferencial competitivo! Ou seja, todos têm de desenvolver a qualidade de produtos, serviços e pessoas para se manter no mercado.
A partir do tema que procuraremos abordar, vamos tentar entender um pouco do universo humano, ao desvendar seu estilo de trabalho (comportamento em grupos sociais), as diferenças de comportamento por faixas etárias e as ferramentas importantes nos dias de hoje para a qualificação dos gestores de informação, destacando o empowerment, como uma metodologia administrativa de se fazer qualidade através das pessoas.

\section{A QUESTÃO HUMANA NA GESTĀO ESTRATÉGICA DE RECURSOS HUMANOS EM UNIDADES DE INFORMAÇĀO}

O ser humano é considerado um animal complexo, dotado de diversas necessidades, que orientam e dinamizam o seu comportamento. (FIG.1).

Diariamente, as pessoas mantêm um relacionamento com a família, amigos, escola, trabalho, clubes etc. Mas, infelizmente, existem aquelas pessoas que não se expõem de forma alguma $\mathrm{e}$, ainda, existem outras que vivem a freqüentar cursos, palestras com o objetivo de aprender a mudar o comportamento... dos outros.

Na maioria das vezes, os administradores ou gerentes fracassam por não conseguirem operacionalizar suas boas intenções em comportamentos que correspondam ao que as pessoas esperam da organização, ou deles mesmos, enquanto seres humanos.

Figura 1. Quais são minhas necessidades

O BIOS que EU SOU tem necessidade de respiração, alimentação, eliminação, sexo e lazer - estão na base da vida.

\section{$\downarrow$}

O PSICO que EU SOU tem necessidade de segurança, previdência como proteção e estabilidade.

O SOCIAL que EU SOU necessita relacionar-se através do amor, amizade, afeição. Para que me relacione tenho que partir de uma referência - O EGO: para ser saudável devo desenvolver a auto-estima através do status, autoconfiança, pagamento e apreço.

O ESPIRITUAL que EU SOU necessita de auto desenvolvimento e autorealização.

O CÓSMICO que EU SOU necessita buscar a transcendência.

FONTE: Referência n 8 deste trabalho 
As pessoas que têm a visão voltada para o futuro e que fazem parte de um grupo, investem nas habilidades individuais, interpessoais e da equipe, estas são valorizadas e fundamentais como elemento no processo de interação e obtenção de resultados positivos. Como qualquer outra prestadora de serviços, a organização de uma unidade de informação tem como seu principal recurso uma equipe bem treinada, capacitada e satisfeita, para atendimento de seus usuários e fornecedores.

Só é possível ter qualidade através das pessoas, e ela se dá através de mudanças de atitudes e comportamentos e também, em muitos casos, de gestão orientada para os processos, nas avaliações constantes e no espírito e na integração da equipe. Inquestionavelmente, a qualidade está ligada à sobrevivência das pessoas, dos seus empregos, das empresas, dos países, do planeta. Não devemos esquecer que menos de $15 \%$ das causas dos erros ocorridos nas empresas estão nas mãos de pessoas e mais de $85 \%$ estão nos processos.

De nada adianta a unidade de informação estar bem estruturada em termos de recursos financeiros, físicos, informativos e pessoal e computacionais se os recursos humanos - que correspondem às pessoas que trabalham - não estão integrados e satisfeitos para assegurar o desempenho global da organização. Estes recursos são os únicos dotados de vida e inteligência para decidir e aplicar os demais recursos existentes. As pessoas são a alma da organização, sem elas os demais recursos não seriam operados, aplicados e ativados (CHIAVENATO, 1994).

Como o mercado está cada vez mais competitivo e exigente, as empresas mais intensamente, e também, as unidades de informação começam a exigir de seus empregados aperfeiçoamento constante. É a busca do potencial humano. Hoje, vivemos a Era do Relacionamento, (FIG. 2) onde o segredo do sucesso não está apenas em ter capital e montar indústrias, mas saber trabalhar com serviços e com a informação e ter habilidades em administrar pessoas. Portanto, é importante que o profissional da informação se integre, assuma o papel de agente ativo nos processos produtivos, além de manter um bom relacionamento com a equipe de trabalho. Assim, em algumas unidades de informação, já existe uma adequação do trabalho ao homem mediante a adequação dos métodos e processos de trabalho, das máquinas e equipamentos, e das condições ambientais de trabalho, quando feitas tornam a relação homem-trabalho mais produtiva e feliz.

a) Produtiva: porque aumenta o rendimento humano;

b) Feliz: porque aumenta a satisfação das pessoas e proporciona um clima de trabalho mais agradável.

Figura 2. As revoluções pelas quais passaram os seres humanos e a atual "era do relacionamento" (4a onda)

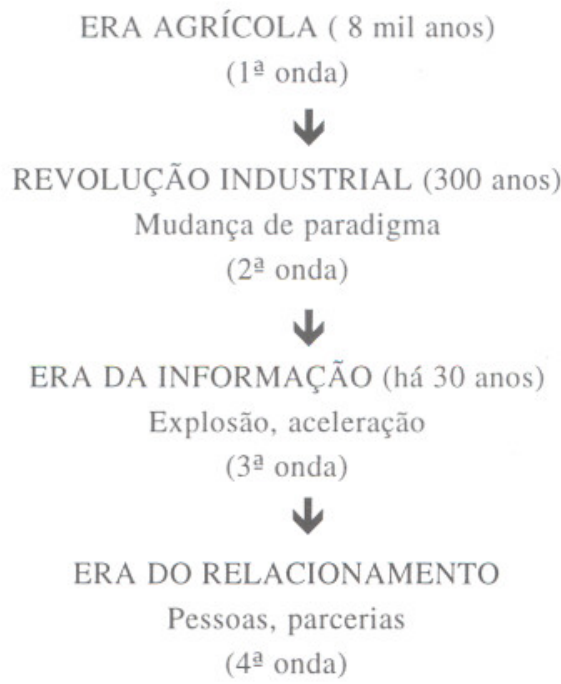

FONTE:Referência nº 8 deste trabalho. 
Quando se consegue este tipo de relação, certamente se consegue a melhoria da qualidade das pessoas para a empresa e a melhoria da qualidade das pessoas na empresa (CHIAVENATO, 1994).

Hoje, a estrutura formal de uma empresa deve estar direcionada para as relações humanas e o comportamento grupal, para a administração participativa e para a clientela, evitando, assim, fragmentar a informação que fica presa na hierarquia, ou melhor dizendo, 'só o topo pensa e a base atua'.

Mudar, direcionar para a real situação da empresa globalizada que acredita nas revoluções, tanto tecnológicas, de gestão e da própria natureza humana - investir nas pessoas, com educação (treinamento) e comunicação (informação); saber e levar em consideração de que apenas 5\% desta comunicação são verbais e os restantes $95 \%$ são percepção, atitude e comportamento.

Como reconhecer e identificar os vários estilos de trabalho das pessoas que trabalham numa empresa/unidade de informação ? A resposta vem do consultor de empresas TALARICO (1997), que define três grandes estilos de comportamento dos grupos sociais no Brasil:

a) o grupo dos necessitados (quase $73 \%$ da população brasileira), pessoas que lutam pela sobrevivência, são esperançosos e inconformados com as injustiças sociais;

b) o grupo dos ajustados (20\%), pessoas integradas, emuladoras e vencedoras;

c) o grupo dos inovadores (7\%), pessoas inquietas e transformadoras.

A partir dessa classificação, é também preciso compreender que os comportamentos dos grupos sociais diferem ao longo de suas etapas de vida (FIG.3).

\subsection{A IMPORTÂNCIA DA LIDERANÇA NO PROCESSO DE MOTIVAÇĀO DOS RECURSOS HUMANOS}

É sabido que na nova visão da Administração Moderna, as relações humanas no trabalho têm prevalência sobre os problemas de organização, matérias-primas, vendas, finanças, etc. Há críticas, no entanto, sobre esta supremacia das relações humanas da parte de pessoas que desenvolvem funções técnicas (coisas, negócios, posições, eficiência e produtividade). Explicando melhor: dentro das organizações há pessoas mais voltadas para a gestão de negócios e pessoas mais voltadas para a liderança de pessoas. Então, líderes e gestores não seriam uma coisa só ? Acreditamos que não, pois, por definição, o líder "é a pessoa que se destaca dentro de um grupo, influenciando-o de alguma forma"; liderança, por sua vez, é um fenômeno social que precisa de existência de uma sociedade e de um ambiente. Ou, nas palavras de PENTEADO (1986), "a liderança é uma função da situação, da cultura, do contexto e dos costumes, tanto quanto é uma função de atributos pessoais e estrutura de grupos. É a combinação equilibrada de três elementos vitais e dinâmicos: o indivíduo, o grupo e a situação."

Figura 3. Negociando com diferentes idades (etapas na vidado serhumano-comportamento)

\begin{tabular}{|c|c|c|}
\hline IDADES & COMPORTAMENTOS & REAÇÕES \\
\hline $0-4$ anos & Atenção & Solidão \\
\hline $5-11$ anos & Identidade & Grupo \\
\hline $12-18$ anos & Conquista & Crítica \\
\hline $19-25$ anos & Autonomia & Relax \\
\hline $26-35$ anos & Profissional & Status \\
\hline $36-45$ anos & Independência & Investimento \\
\hline $46-55$ anos & Segurança & Estrutura \\
\hline $56-65$ anos & Experiência & Grupo \\
\hline $65-85$ anos & Atenção & Solidão \\
\hline
\end{tabular}

FONTE: Referência n. ${ }^{\circ} 9$ deste trabalho

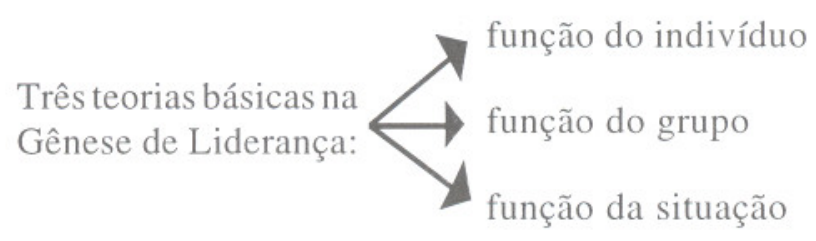

$\mathrm{E}$, inclusive, na literatura, existe a teoria denominada Teoria das Pessoas Centrais de Reidel, cujo mérito está em confirmar ser a Liderança uma qualidade global do indivíduo mais do que um traço de caráter, só que, ou são voltados mais para a condução dos negócios, ou são mais para a condução de pessoas (PENTEADO, 1986). 
Na verdade, são muitas as qualidades de um bom líder, porém, essas qualidades independem dos processos tradicionais de liderança, a saber: autoritário, democrático ou liberal.

Além das condições de autenticidade, transitoriedade, autoridade e responsabilidade, caberá ao líder a sua função maior, qual seja, a função da arte de delegar tarefas à sua equipe.

A par destas considerações sobre o papel do líder/liderança, agora, passemos a distinguir o papel dos gestores de unidades de informação, começando pelo conceito básico de gestão, encontrado no Manual Gestão de Unidades de Informação, do IBICT/TECPAR (1997):

A gestão consiste não só de um conjunto de ferramentas, como também de uma adequada visão e compreensão do negócio em si. A gestão não é ciência propriamente dita em que resultados pré-estabelecidos são fatalmente obtidos quando se aplicam métodos prescritos. As leis de causas e efeitos muitas vezes se baseiam em modelos bastante incompletos da realidade, tendo em vista a sua própria complexidade e extensão. É notória a importância da intuição empresarial, que no fundo reflete a percepção correta do negócio. Ao longo deste Manual, as ferramentas, os métodos e os conceitos são apresentados com a indicação de sua aplicação e o leitor deverá se esforçar para visualizar a informação como o seu negócio, deverá conceber uma idéia global dos seus mercados, dos seus clientes e fornecedores, das práticas comerciais, dos hábitos e costumes que formam a cultura na qual está inserido o seu negócio que é Informação, e como seu negócio interage e é afetado pelo restante da sociedade, deverá também compreender em grandes linhas no que consiste a atividade de gestão e qual o seu papel em uma Unidade de Informação.

Vê-se com efeito que o termo gestão tende muito mais para negócios do que para pessoas, propriamente. Ou seja, a informação é o grande negócio promissor de nossa época, por sua funcionalidade.

Qual seria, então, a principal preocupação (desafio) daqueles que pretendem exercer o papel de gestores de unidades de informação ? Conforme o próprio MANUAL, "a preocupação de um gestor deve ser a de compreender o papel da informação nas sociedades atuais e como esse recurso estratégico é produzido, transportado e utilizado.(...)"(1997).

Entendemos que estas preocupações restringem-se, somente, às dimensões: a) estratégica (empreendimentos que servem e interagem com diversos segmentos da sociedade); b) operacional (nos níveis de execução e o desenrolar dos trabalhos efetuados pelo grupo).

As dimensões psicológica e social, enquanto funções humanas por excelência, ficam relegadas a um segundo plano. Muitas unidades de informação existem, sem, no entanto, saber exatamente qual o seu papel e como avaliar se estão cumprindo-o adequadamente (MANUAL, 1997).

Enquanto as unidades de informação/ bibliotecas não definirem claramente: a sua missão e seus objetivos; os resultados a serem gerados por sua ação; os beneficiários desses resultados e os indicadores de seu sucesso, não conseguirão valorizar os aspectos elencados abaixo, para a motivação de seus recursos humanos (FIG.4).

Figura 4. Aspectos essenciais para a motivação e correta gestão de Recursos Humanos

- valorização do ser humano;

- incentivo ao desenvolvimento e uso da criatividade;

- reconhecimento, valorização e abertura de espaço para a realização de mudanças e aplicação de inovações;

- imposição de desafios individuais e coletivos;

- homogeneidade de interesses, pensamento, dedicação e esforço na equipe

FONTE: referência nº 4 deste trabalho.

\section{COMO OBTER QUALIDADE ATRAVÉS DAS PESSOAS}

O desenvolvimento da empresa deve abranger todos os aspectos: do planejamento estratégico aos padrões de produção. Empresas de sucesso são feitas por pessoas vencedoras, que dão sempre o melhor de si, porque percebem que 
estão sendo valorizadas e estimuladas, concorrendo para um aumento da produtividade e qualidade daquilo que fazem. Ao se buscar e incentivar a motivação, a criatividade e a participação das equipes de trabalho, estará sendo obtido um grande diferencial competitivo, neste mercado cada dia mais exigente.

Nenhuma unidade de informação conseguirá realmente lograr êxito se não organizar e gerenciar adequadamente: o uso correto do tempo nas organizações ( administração do tempo); seus processos de produção (transformação de bens culturais ou criação de utilidades); a implantação de princípios da Qualidade Total; uma administração participativa. Nem tampouco, obter satisfação na prestação de seus serviços, junto a seus usuários, fornecedores e colaboradores (equipe).

Esta situação poderá ser revertida, se lembrarmos de algumas atribuições importantes aos gestores de recursos humanos:

- ter autonomia e saber a quem dar atribuições;

- ter a visão global da empresa: tanto dos objetivos empresariais como pessoais;

- conhecer as novas tecnologias e as novidades do mercado;

- personalidade: habilidade no tratamento com pessoas ( saber liderar, motivar e avaliar);

- ensinar e estimular o autogerenciamento da equipe (programas e políticas de desenvolvimento).

Pensamos que através dessas atribuições, os gestores de unidades de informação/biblioteca gozarão de maior empatia da parte de seus colaboradores, usuários e fornecedores, ao:

- saber chefiar e liderar por meio de uma administração participativa, que suprima o discurso do eu", para o discurso do "nós";

- recrutar e selecionar pessoas que se adaptam rapidamente ao novo local de trabalho;

- gerenciar equipes de trabalho com uma justa divisão de tarefas e de responsabilidades;

- qualificar e motivar seus recursos humanos, para os objetivos traçados;

- saber delegar informações e autoridade, descentralizando as decisões, pois são através delas que se obtém agilidade na empresa;

- propiciar o autoconhecimento pessoal, visando a integração grupal, ao fortalecer o espírito de equipe;

- avaliar as potencialidades de sua equipe de trabalho, promovendo uma avaliação de desempenho, calcada nos seguintes aspectos: o desempenho técnico do funcionário, que são as habilidades que ele possui para desempenhar as atividades sob sua responsabilidade, o seu potencial para assumir novas responsabilidades (elementos comportamentais); a sua disposição para desenvolver trabalhos em grupo, o seu interesse em atualizar-se e aprimorar-se naquilo que faz.

Com certeza, gestores de unidades de informação eficazes são aqueles que atingem resultados através de pessoas (equipes) motivadas e unidas, sabem como estabelecer metas pessoais e profissionais em suas carreiras, ou seja, têm um novo perfil: o dos gestores-empreendedores, que sabem conquistar e manter seus usuários, levantando suas necessidades, expectativas e desejos e, a partir daí, surpreendê-los positivamente com novos produtos e/ou serviços. Vêem na qualidade do atendimento aos usuários e na criatividade, os grandes diferenciais nos níveis de satisfação. Portanto, os novos desafios para esses gestores, são agora: criatividade e profissionalismo.

\section{O EMPOWERMENT ENQUANTO METODOLOGIA ADMINISTRATIVA PARA FAZER QUALIDADE DE PRODUTOS, SERVIÇOS E, PRINCIPALMENTE, PESSOAS}

Por muitos anos prevaleceu a idéia de que para uma pessoa assumir um cargo de liderança, esta devia tê-la como qualidade pessoal e que era determinada por características de personalidade. Já sabemos que, o líder pode ser formado, ele não nasce pronto. É ele que vai criar condições para o bom desempenho dos seus colaboradores e propiciar a sua satisfação na execução de suas tarefas, através da criação, do alcance e da sustentação de alvos determinados a serem atingidos por toda a equipe. Trabalhar em equipe leva a resultados mais eficazes do que trabalhar sozinho, onde o sucesso de um é o sucesso de 
todos, onde ninguém "afunda o barco sozinho", todos são responsáveis pelo resultado obtido.

Algumas sugestões que podem ser aplicadas na equipe a fim de facilitar e propiciar a participação ativa de todos o seus membros:

- cada pessoa tem o seu lugar - devem ser valorizadas e respeitadas;

- liberdade para falhar;

- enfocar o positivo e as potencialidades humanas;

- reconhecimento pela gerência e demais colegas de trabalho;

- oportunidades de progresso, como perspectivas de ascensão a médio e longo prazos;

- eliminar o trabalho não produtivo e propiciar trabalho interessante e com remuneração adequada.

De acordo com STRUGALE \& BERTONCELLO (1997),trabalhar juntos é uma conquista que demanda conhecimento, informação, paciência, perseverança e fé. É conquista de detalhes, de pequenas coisas e, principalmente, do novo. No verdadeiro espírito de equipe o individualismo se dilui, desaparecendo o eu para dar lugar ao nós, onde o meu sucesso e o sucesso do outro são interpendentes.

Uma das ferramentas da gestão estratégica de recursos humanos - o empowerment, que ao lado de outras ferramentas, tais como: a qualidade total, o benchmarking, ISO 9000, a reengenharia e o downsizing, "proporcionam um aumento da eficiência nos processos operacionais" (MONTENEGRO, 1998). Contudo, para que o empowerment se torne um elemento altamente diferenciador e que, por conseguinte, proporcione uma vantagem competitiva sustentável, as pessoas continuarão a ser o mote de nossas reflexões.

Empowerment, do verbo inglês " $t o$ empower", etimologicamente, significa transferir ou investir poder em algo ou alguém. Este transferir, para STRUGALE \& BERTONCELLO, “é principalmente atitude e exemplo através da convivência. É muito mais que palavras". (1997).

Como nenhuma pessoa neste planeta está inerte, nem neutra, logo todas as pessoas estão influenciando outras pessoas, ao mesmo tempo em que também, são influenciadas para o bem ou para o mal! Haja vista a quantidade de investimentos em armamentos químicos, nucleares, biológicos, etc. (mesmo após a Guerra Fria) se comparados aos investimentos em erradicação da fome e do analfabetismo no mundo. Fica claro que o preparo para a destruição é bem maior que o preparo para a paz ...

O que cada um de nós precisaria refletir mais é sobre o quanto afetamos as pessoas com quem convivemos, posto que, o mundo externo é só um reflexo de nosso mundo interno. O empowerment, nessa ótica, começa por aqui:

- o que estou refletindo no mundo?

- estou contribuindo para a paz ou para a guerra?

- que tipo de exemplo eu sou na família, entre amigos, na empresa?

- afinal, quem sou eu?

Como transpor estas questões para o ambiente de unidades de informação ? Começando por mostrar uma conceituação do empowerment extraída da literatura: "é colocar a decisão o próximo possível da ação." Nas empresas, os processos de empowerment buscam fazer com que as pessoas nos níveis hierárquicos mais baixos se sintam com poder para agir e que de fato o façam, assumindo responsabilidades pelas decisões (STRUGALE \& BERTONCELLO, 1997). Vê-se que este conceito vai muito além da arte de delegar autoridade e de treinamento adicional. Por quê? Significa encorajar as pessoas a tomarem decisão, ampliando os seus raios de ação, mesmo quando erros forem cometidos.

O verdadeiro ambiente do empowerment é aquele em que as pessoas se sentem comprometidas com a organização e passam a ter um maior senso de responsabilidade. A metodologia do empowerment se volta para o Homem Interior. E lá é que nasce o compromisso, a motivação, a qualidade.

Trata-se da ferramenta mais adequada para se evitar o desperdício dos talentos humanos dentro das organizações, evitando-se o desperdício de toda ordem, na ótica do Sumário 
Figura 5. Sumário

\section{CONCEITO}

Decisão junto de ação

ת

\section{REDESCOBERTA DO ÓBVIO}

$\mathrm{O}$ mundo externo é reflexo do mundo interno

』

\section{EMPOWERMENT COMEÇA POR AQUI}

Que tipo de mundo estou construindo?

ת

\section{SOU EXEMPLO, SEMPRE}

\section{ภ}

\section{ESTA ATITUDE AJUDA A CRIAR}

Ambiente de empowerment

previne: desperdício dos talentos humanos

Possibilita: compromisso, motivação, qualidade

FONTE: Referência nº 8 deste trabalho.

das autoras STRUGALE \& BERTONCELLO (1997) (FIG. 5).

Os gestores-empreendedores que compreenderem (em tempo) que o próximo milênio já começou no início desta década; que terão de mudar o alvo de sua atenção gerencial, passando de uma visão apenas tecnicista, para outra, mais humanística e holística, calcada em "valores éticos, existenciais, funcionais e evolucionais" (MONTENEGRO, 1998), e que não deverão se curvar ante a conjuntura globalizante e alienante, a eles e à sua equipe triunfadora, por certo, caberão o mérito do desenvolvimento cientítico/tecnológico e humanístico porque passam o país.

\section{CONCLUSŌES}

O princípio norteador deste trabalho resumese, enfim, à proposição segundo a qual os aspectos psicológicos e sociológicos da atuação dos gestores de unidades de informação têm sido pouco praticados na realidade

Dessa proposição tentou-se mostrar que o maior recurso que uma unidade de informação pode ter é uma equipe qualificada, treinada e motivada. O desejo de se trabalhar com uma pessoa de alta capacidade e preparo e que, por sua vez, esteja entusiasmada com o trabalho que executa, é comum em qualquer lugar ou situação. Somente a experiência anterior não basta, é necessário para que um profissional integre uma equipe, é necessário um crescimento pessoal e profissional gradativo, alcançado através de oportunidades de atualização e capacitação técnica, a exemplo do empowerment.

Para que o desenvolvimento de pessoal se torne parte integral das operações e uma unidade de informação, a administração deve tornar conhecidas as oportunidades para os colaboradores. Deve, ainda, integrá-los na formulação de programas e políticas de desenvolvimento, a fim de criar espírito de equipe e proporcionar uma ambiente motivado. Essa integração fará com que a unidade de informação seja um lugar onde as pessoas gostarão de trabalhar e se sentirão satisfeitas.

Passou-se a analisar, então, uma das ferramentas da gestão estratégica de recursos humanos chamada empowerment, que vem a contribuir com uma visão mais humanística no trabalho dos gestores, na medida em que procura decentralizar as decisões estratégicas junto das ações. Para tanto, procurou-se traçar um paralelo entre o papel dos líderes e gestores, para compreender que ambos devem desenvolver habilidades individuais, interpessoais e da equipe no processo de motivação dos recursos humanos.

Finalizando, as técnicas e métodos de gestão, de um lado, e a motivação e liderança de equipes, de outro, constituem duas vertentes distintas, porém, não excludentes, da gerência estratégica de empresas ou de unidades de informação.

\section{REFERÊNCIAS BIBLIOGRÁFICAS}

1 ASSIS, Dario Crispim de; CRISTIANINI, Glaucia M. Saia. Administrando a (des)motivação nas bibliotecas universitárias. In: SEMINÁRIO NACIONAL DE BIBLIOTECAS UNIVERSITÁRIAS (9.:1996: Curitiba). Anais. Curitiba: Biblioteca Central, 1996.

2CATÁLOGO de treinamento empresarial junho/julho/ agosto/98 do SEBRAE/PR.

3 CHIAVENATO, Idalberto.Iniciação de administração de pessoal. São Paulo: Makron Books, 1994.

4 MANUAL de gestão de unidades de informação. Curitiba: TECPAR; Brasília: IBICT, 1997. 
5 MONTENEGRO, Eraldo de Freitas; BARROS, Jorge Pedro Dalledonne de. Gestão estratégica : a arte de vencer desafios. São Paulo: Makron Books, 1998.

6 PENTEADO, José Roberto Whitaker. Técnica de chefia e liderança. 7. ed. São Paulo: Pioneira, 1986.

7 RAMOS, Paulo A B. A gestão na organização de unidades de informação. Ciência de Informação, Brasília, v. 25, n. 1, p. 15-25, jan./abr.1996.
8 STRUGALE, B. H. K.; BERTONCELLO, Jussara M. Empowerment: como obter qualidade através de pessoas. Curitiba: Sebrae, 1997. (Curso)

9 TALARICO, Edison. Quebrando paradigmas e estabelecendo novas formas de pensar. teleconferência proferida naEMBRATEL, Curitiba, 2 de fev. 1997.

10 VIANNA, Marco A Ferreira. Os desafios da competitividade: os atributos da empresa triunfadora. Teleconferência proferida na EMBRATEL, Curitiba, 25 de fev. 1996. 